UNIVERSIDADE DE SÃO PAULO

ESCOLA DE EDUCAÇÃO FÍSICA E ESPORTE DE RIBEIRÃO

PRETO

WESLLEY MATHEUS MALACHIAS

Auto-organização do jogo de basquetebol: flutuações do sistema e suas influências.

RIBEIRÃO PRETO

2021 
WESLLEY MATHEUS MALACHIAS

\section{Auto-organização do jogo de basquetebol: flutuações do sistema e suas influências.}

\section{Versão Corrigida}

Dissertação apresentada à Escola de Educação Física e Esporte de Ribeirão Preto da Universidade de São Paulo, para obtenção do título de mestre em Ciências, Programa de Pós-graduação em Educação Física e Esporte.

Area de concentração: Atividade física e esporte.

Orientador: Prof. Dr. Márcio Pereira Morato

RIBEIRÃO PRETO 
Autorizo a reprodução e divulgação total ou parcial deste trabalho, por qualquer meio convencional ou eletrônico, para fins de estudo e pesquisa, desde que citada a fonte.

Malachias, Weslley Matheus

Auto-organização do jogo de basquetebol: flutuações do sistema e suas influências. Ribeirão Preto, 2021. $45 \mathrm{p}$.

Dissertação de Mestrado, apresentada à Escola de Educação Física e Esporte de Ribeirão Preto/USP.

Area de concentração: Atividade física e esporte.

Orientador: Morato, Márcio Pereira.

1. Ciência do esporte. 2. Basquetebol. 3. Análise de jogo.

4. Auto- organização. 
Nome: Weslley Matheus Malachias

Título: Auto-organização do jogo de basquetebol: flutuações do sistema e suas influências.

Dissertação apresentada à Escola de Educação Física e Esporte de Ribeirão Preto da Universidade de São Paulo, para obtenção do título de mestre em Ciências.

Aprovado em:

\section{Banca Examinadora}

Orientador: Prof.Dr. Márcio Pereira Morato.

Instituição: Universidade de São Paulo - Escola de Educação Física e Esporte de Ribeirão Preto.

Julgamento:

Assinatura:

Prof ${ }^{a}$.Dr吕. Larissa Rafaela Galatti

Instituição: Faculdade de Ciências Aplicadas - Universidade De Campinas.

Julgamento:

Assinatura:

Prof.Dr. Paulo Cesar Montagner

Instituição: Faculdade De Educação Física - Universidade De Campinas.

Julgamento:

Assinatura:

Prof.Dr. Rafael Pombo Menezes

Instituição: Universidade de São Paulo - Escola de Educação Física e Esporte de Ribeirão Preto.

Julgamento:

Assinatura: 
MALACHIAS, Weslley Matheus. Auto-organização do jogo de basquetebol: flutuações do sistema e suas influências. 2021. 40 p. Dissertação (Mestrado em Educação Física e Esporte) - Escola de Educação Física e Esporte de Ribeirão Preto, Universidade de São Paulo, Ribeirão Preto, 2021.

\section{RESUMO}

Devido ao dinamismo dos eventos durante suas partidas, os esportes coletivos devem ser entendidos como sistemas complexos e dinâmicos. Assim, o objetivo principal desta pesquisa foi compreender a auto-organização do jogo de basquetebol, por meio de uma classificação baseada no final dos processos ofensivos. Foram analisadas todas as partidas de basquetebol masculino dos Jogos Olímpicos Rio 2016. O protocolo de análise se baseou em variáveis de ação do jogo e posterior classificação da finalização de cada processo ofensivo: Não finalizado (processos que não geraram finalização ao alvo), 0 ponto (processos finalizados que não geraram pontos), 1 ponto (processos gerando 1 ponto), 2 pontos (processos gerando 2 pontos), 3+ pontos (processos gerando mais de 3 pontos). Também foram investigados os rebotes, setores de finalização dos ataques, estado do jogo e a duração dos ataques. Utilizouse o teste qui-quadrado para comparar as frequências das ações e dos processos ofensivos. O teste $T$ foi utilizado para o comparativo entre equipes vencedoras vs. perdedoras e equipes superiores vs. inferiores. As equipes vencedoras obtiveram mais processos ofensivos de 2 pontos $(35,3 \%$ vs. $30,6 \%), 3+$ pontos $(14,7 \%$ vs. $10,8 \%$ ) e menos processos 0 ponto $(28,5 \%$ vs. $35,0 \%)$ com $p<0,05$. Na comparação entre equipes superiores e inferiores, foi encontrado que a classificação $3+$ pontos não demonstrou diferença significativa, como no cenário das partidas. Com relação aos rebotes, foi encontrada diferença significativa para todas as categorias analisadas nas partidas; no campeonato foi identificada diferença apenas na categoria sem rebote. Os locais de finalização do ataque demonstraram significância no campeonato, com as equipes superiores apresentando um maior volume de ações na região mais próxima da cesta. Os resultados encontrados demonstram que a finalização ao alvo é o principal atrator do jogo, com a classificação 2 pontos sendo o principal balizador de sucesso. As flutuações mais relevantes são representadas pelas classificações sem finalização e 3+ pontos. Tal ferramenta demonstrou valia para a compreensão da autoorganização do basquetebol e apresenta uma nova possibilidade de analisar o jogo. Acreditamos que pode servir como uma análise diagnóstica que auxilie no processo jogo, análise e treinamento para um melhor entendimento do jogo de basquetebol em diferentes contextos.

Palavras-chave: Ciência do esporte. Basquetebol. Análise de jogo. Autoorganização. 
MALACHIAS, Weslley Matheus. Self-organization of the basketball game: system fluctuations and their influences. 2021. 31 p. Masters Dissertation (Master in Physical Education and Sport) - Escola de Educação Física e Esporte de Ribeirão Preto, Universidade de São Paulo, Ribeirão Preto, 2021.

\begin{abstract}
Due to the dynamism of the events during their matches, team sports must be understood as complex and dynamic systems. Thus, the goal of this research was to understand the self-organization of the basketball game, through a classification based on the end of the offensive processes. All male basketball matches of the 2016 Olympic Games - Rio de Janeiro were analyzed. The analysis protocol was based on game action variables and subsequent classification of the completion/finish of each offensive process: Not throw (offensive process that didn't generate shot to the basket), 0 points (offensive process that didn't generate points), 1 point (offensive process generating 1 point), 2 points (offensive process generating 2 points), $3+$ points (offensive process generating 3 or more than points). Rebounds, location of attack completion, match status and duration of attacks were also investigated. The chisquare test was used to compare the frequency of offensive actions and offensive process. T test was used to compare winning team's vs teams losers and top team's vs lower teams. The winning teams had more offensive processes of 2 points $(35.3 \%$ vs. $30.6 \%), 3+$ points $(14.7 \%$ vs. $10.8 \%)$ and less 0 points $(28.5 \%$ vs. $35.0 \%)$ with $p$ $<0.05$. When comparing upper and lower teams, the classification $3+$ points showed no significant difference, as in the scenario of the matches. About rebounds, significant difference was found for all categories analyzed in the matches. However, in the championship a difference was identified only in the category without rebound. Location of attack completion were only significant in the championship with the top teams presenting a greater volume of attacks in the region closest to the basket. The results found demonstrate that finishing the basket is the main attractor of the game with the classification 2 points being the main marker of success. The most relevant fluctuations are represented by the classifications Not throw and 3+ points. This tool has demonstrated value to the understanding of the self-organization of basketball and presents a new possibility to analyze the game. We believe it is a diagnostic analysis that helps in the process: match, analysis and training for a better understanding of the game of basketball in different contexts.
\end{abstract}

Key words: Game analysis; Basketball; Dynamic systems; Offensive processes. 


\section{SUMÁRIO}

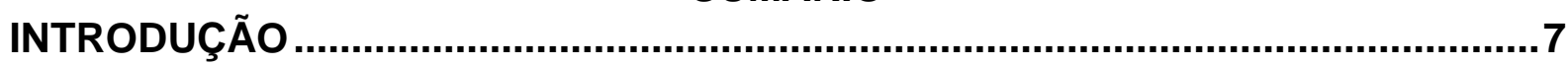

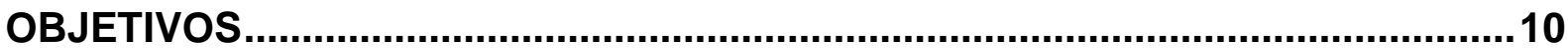

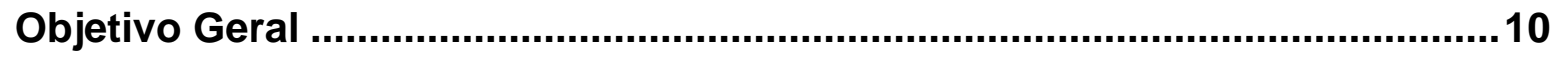

Objetivos Específicos........................................................................................10

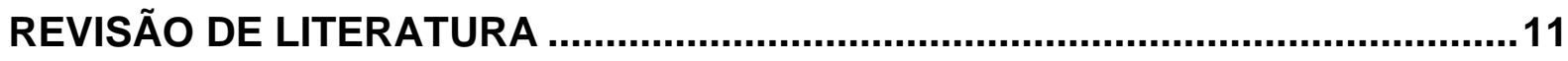

MÉTODO

Protocolo de observação e classificação do processo ofensivo .....................18

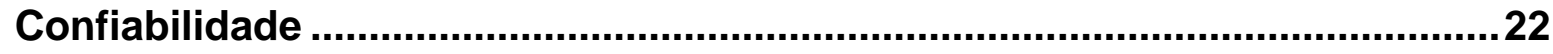

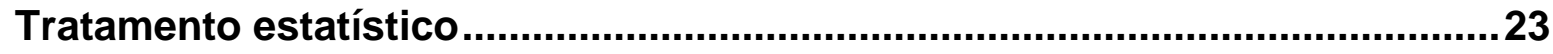

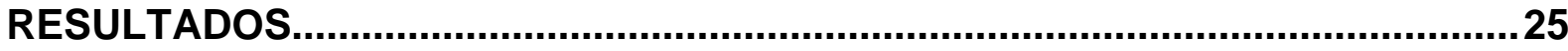

DISCUSSÃO

CONCLUSÃO

REFERÊNCIAS

ANEXO 1 


\section{INTRODUÇÃO}

Os esportes coletivos são práticas esportivas nas quais duas equipes se enfrentam com o objetivo de demonstrar superioridade sob seu adversário nas mais diversas formas de pontuação (MENEZES; MARQUES; NUNOMURA, 2014). Nos esportes coletivos encontramos os esportes coletivos de invasão que são compostos por algumas particularidades como o confronto das duas equipes em espaço mútuo e simultâneo além de ser permitida a intervenção direta no implemento (LEONARDO; SCAGLIA; REVERDITO, 2009). O basquetebol, como uma modalidade esportiva coletiva de invasão, tem em sua dinâmica um jogo com características de cooperação e oposição, envolvendo ações sucessivas de ataque e defesa, alternadas entre as equipes (GALATTI et al.,2015; PROCHNOW et al., 2017).

Para Bayer (1994) as origens dos jogos esportivos coletivos desde cedo são parte do patrimônio cultural das civilizações. $O$ autor detalha o entendimento sobre os jogos esportivos coletivos de maneira que conceitos são considerados invariantes a todos os esportes:

(a) Bola/implemento: objeto determinado por regras restritas de acordo com cada modalidade que pode ser usada tanto com as mãos ou pés.

(b) Terreno: espaço para o confronto das equipes, sendo idêntico para todos os participantes, que pode ser compartilhado com os adversários como nos jogos esportivos coletivos de invasão ou reservado a cada equipe como em esportes de rede.

(c) Balizas: delimitador do objetivo do jogo, seja por meio de marcações no solo, traves, aros como no basquetebol ou podendo se manifestar de outras maneiras em outros esportes.

(d) Regras do jogo: leis das quais os agentes do jogo têm de respeitar, orientando a maneira pela qual a partida deve ocorrer. $O$ árbitro é aquele que gerencia o jogo com suas regras e quem aplica as sanções para aqueles que não a respeitarem. 
(e) Parceiros: os parceiros são tratados como fator de cooperação nos jogos, buscam atingir um objetivo comum que seria superar os adversários e são tratados como uma possibilidade de ajuda funcional na realização do objetivo coletivo.

(f) Adversários: tem como objetivo criar situações adversas para a equipe oposta, buscando demonstrar superioridade e trabalhar em prol de um resultado positivo.

Devido a esses denominadores em comum os jogos esportivos coletivos são interligados por princípios básicos ofensivos e defensivos conforme a posse da bola, a equipe atacante com princípios de conservar a posse da bola, progressão dos parceiros e bola ao alvo e finalizar ao alvo. A defesa tem que recuperar a posse da bola, impedir a progressão de adversários e bola e se proteger de finalizações (BAYER, 1994). Devido ao alto dinamismo dos jogos esportivos coletivos de invasão a fase de transição se torna relevante, uma vez que desequilíbrios numéricos e espaço temporais nesta fase podem causar grandes instabilidades. Os princípios a serem seguidos nas transições ofensivas das equipes são: buscar controlar a bola após recuperação, encontrar zonas propícias para progressão, alcançar vantagens numéricas ou espaciais e finalizar de zonas efetivas buscando desequilibrar o adversário. Na transição defensiva a equipe busca: pressionar o adversário em posse da bola, retornar antecipadamente para o campo de defesa, proteger os setores defensivos de maior efetividade e induzir o adversário para um ataque posicional (MENEZES; MARQUES; MORATO, 2016).

Por apresentarem a peculiaridade do alto dinamismo e de relações complexas, os jogos esportivos coletivos de invasão podem ser compreendidos como sistemas dinâmicos (GRÉHAIGNE; BOUTHIER; DAVID, 1997; MCGARRY et al., 2002; PASSOS; ARAÚJO; DAVIDS, 2013; REED; HUGHES, 2006). Tais sistemas têm como característica a troca constante de informações para manter sua organização. O sistema se configura de maneira que as relações entre os agentes geram comportamentos imprevisíveis. Tal troca de informações pode também inibir comportamentos inerentes dos seus agentes para que a organização do sistema mantenha uma lógica. Reconhecer que o sistema é imprevisível é vital para compreender os processos de auto-organização do sistema (MORATO; GOMES; ALMEIDA, 2012). A auto-organização se caracteriza como uma organização, que provém de interações das atividades do sistema. Tal processo não possui padrões de formação e evolução de modo predeterminado, uma vez que existe sempre a 
possibilidade de mudança de estado do sistema (D'OTTAVIANO; BRESCIANI FILHO, 2004).

Nos esportes coletivos de invasão podemos tratar a auto-organização como a maneira pela qual as equipes se comportam sob variadas situações apresentadas durante as partidas (MENEZES, 2012). Durante os confrontos, as equipes podem ser consideradas como sistemas independentes que influenciam o jogo e se influenciam mutuamente por suas interações. Dessa maneira, as equipes estarão sempre envolvidas numa relação antagônica em relação ao ataque e defesa, tratando a partida como um sistema maior (BARRAGÁN, 2015; GRÉHAIGNE; BOUTHIER; DAVID, 1997; MCGARRY et al., 2002; MORATO; GOMES; ALMEIDA, 2012). Esse antagonismo entre as equipes traz ao jogo uma estabilidade em sua dinâmica, formando um ciclo lógico que tende a se repetir. Tal ciclo pode ser considerado como um atrator do sistema, o atrator é uma condição que influencia todo o sistema e o força a assumir determinado padrão (MORATO; GOMES; ALMEIDA, 2012).

Mesmo com a ação dos atratores no jogo, pequenas modificações no sistema podem causar alterações quando ele se reorganiza (MCGARRY et al., 2002). Tais alterações são consideradas flutuações. As flutuações podem ser entendidas como regiões instáveis do sistema jogo, causando disparidade na resposta comportamental das equipes perante a partida. Flutuações negativas buscam manter o sistema próximo de sua estabilidade, mantendo a equipe mais próxima dos padrões e coibindo modificações extremas. As flutuações positivas buscam aumentar a instabilidade do sistema, levando equipes para situações não esperadas no padrão de jogo (HUGHES; FRANKS, 2007; MORATO; GOMES; ALMEIDA, 2012). As flutuações podem ser geradas por diferentes eventos durante o jogo. Na sua ocorrência, as equipes podem tentar intervir para conseguir possíveis vantagens, como em uma situação de expulsão ou troca de um jogador relevante ou, até mesmo, encontrando espaços e estratégias durante as partidas que facilitem a pontuação (GRÉHAIGNE; BOUTHIER; DAVID, 1997; HUGHES; FRANKS, 2007; MORATO; GOMES; ALMEIDA, 2012) 


\section{OBJETIVOS}

\section{Objetivo Geral}

O objetivo principal foi compreender o processo de auto-organização do jogo de basquetebol masculino no contexto dos Jogos Olímpicos na edição de 2016 por meio de uma classificação baseada no final dos processos ofensivos.

\section{Objetivos Específicos}

- Identificar a normalidade do sistema-jogo encontrado nas partidas de basquetebol do contexto analisado.

- Encontrar possíveis flutuações existentes no sistema-jogo nas partidas de basquetebol do contexto analisado.

- Analisar a influência das possíveis flutuações no desempenho das equipes vencedoras e perdedoras das partidas.

- Analisar a influência das possíveis flutuações no desempenho das equipes semifinalistas comparadas com as demais equipes que disputaram o campeonato analisado. 


\section{REVISÃO DE LITERATURA}

Os sistemas dinâmicos permitem observar o basquetebol em sua plenitude, de modo a entender suas interações com os agentes e os problemas de gerenciamento que o jogo apresenta: I) espaço-temporais; II) informacionais e III) organizacionais (GRÉHAIGNE; BOUTHIER; DAVID, 1997; MENEZES, 2012). Tais interações produzem um alto grau de imprevisibilidade e complexidade ao jogo, pois existe uma infinidade de comportamentos, orientados pela estrutura, funcionalidade e dinâmica do jogo, sendo executados ao mesmo tempo pelas equipes em disputa (GRÉHAIGNE; BOUTHIER; DAVID, 1997; MCGARRY et al., 2002; MENEZES, 2012; PERL, 2004). De Rose e Tricoli (2005) apresentam que o jogo de basquetebol tem a particularidade de se desenvolver na maior parte do seu tempo em um espaço reduzido de meia quadra, acentuando a luta pela posse de bola e ao alcance do objetivo final do jogo: a conversão da cesta. Desta maneira temos os sistemas ofensivos classificados como posicionado e contra-ataque. Posicionado sendo os momentos com mais passes e buscando espaços e situações favoráveis para a finalização. Os contra-ataques são situações de transição ofensiva que buscam o desequilíbrio defensivo com uma rápida progressão no campo e finalização ao alvo. Na defesa encontramos os seguintes sistemas (DE ROSE; TRICOLI, 2005):

(a) Individual: com um foco na marcação em uma relação de um jogador marcando diretamente seu oponente.

(b) Zonas: com cada jogador tendo uma relação mais ligada ao espaço e a movimentação da bola do que aos jogadores adversários.

(c) Pressão: sistema defensivo que busca diminuir os espaços do adversário, aumentar a intensidade para a retomada da posse de bola e impossibilitar a aproximação da cesta.

(d) Misto: Utiliza elementos da marcação por zona e da marcação individual, com alguns jogadores preocupados em ocupar espaços específicos do campo de jogo e outros com atenção voltada para jogadores demarcados da equipe adversária.

(e) Combinado: A defesa combinada se caracteriza por se posicionar como uma defesa por zona, porém os jogadores buscam acompanhar os jogadores no seu setor 
e conforme o adversário se movimenta entre os setores a equipe troca as marcações buscando manter um equilíbrio de espaço e diminuir o espaço de ação de cada jogador.

Uma vez que os estudos buscando analisar os indicadores de desempenho no basquetebol relacionados à fase defensiva são escassos Gómez, Evangelos e Alberto (2006) buscaram compreender a importância de cada sistema defensivo analisando 1450 posses de bola ocorridas na fase final do campeonato Espanhol de basquetebol na temporada 2004/05. Com relação a defesa enfrentada, foi encontrado que as equipes vencedoras atacam mais vezes as defesas do tipo mistas e individual com pressão, que defende menos a cesta e busca causar mais constrangimento ao jogador adversário. As equipes perdedoras atacaram mais vezes defesas individuais em meia quadra defensiva, que defendem mais a cesta e busca trazer menos constrangimentos em relação ao jogador. Álvarez et al. (2009) analisaram diferentes indicadores defensivos e os relacionaram com o sucesso das ações e o resultado das partidas. Foram analisadas 1045 jogadas de 8 partidas eliminatórias dos Jogos Olímpicos de 2008. Foi encontrado que a defesa mais utilizada foi a de marcação individual, porém a que apresentou maior eficácia foi a marcação por zona. Existiu pressão nas transições em 23,8\%, com eficácia de 50,2\%. A ajuda na defesa provou ser um recurso muito importante nas partidas analisadas sendo utilizada em $60 \%$ dos ataques observados. Com relação a oposição nos arremessos, 38,9\% dos arremessos são realizados com muita oposição defensiva, com uma taxa de conversão de $42,5 \%$. Também foi constatado que $42,2 \%$ dos ataques geraram pontuação, sendo que as equipes vencedoras sofreram pontuação em apenas 38,8\% dos ataques, enquanto os times perdedores permitiram que $45,7 \%$ fosse transformado em pontuação.

Devido a sua grande complexidade e seu dinamismo, o jogo de basquetebol pode apresentar diferenças nas suas dinâmicas e nas tarefas executadas pelos seus agentes, seja pelo nível de familiaridade com o jogo, relação cultural com a prática e outros elementos ambientais que podem interferir durante uma partida. A literatura relacionada à análise de jogo no basquetebol tem buscado encontrar evidências que demonstrem como as equipes obtém sucesso nas partidas, diferentes fases do campeonato e momentos específicos do jogo. Com esses esforços a comunidade 
científica vem encontrando alguns denominadores em comum em diferentes contextos analisados.

Analisando confrontos continentais, Trninić, Dizdar e Lukšić (2002) buscaram identificar quais parâmetros estariam mais próximos de apontar uma equipe vitoriosa nos confrontos de semifinais e finais do campeonato Europeu de clubes. Foram analisadas as edições de 1992 até o ano de 2000 totalizando 36 partidas. Os resultados demonstraram que as equipes vencedoras obtiveram melhor desempenho em: lances livres convertidos, arremessos convertidos de dois e três pontos e mais rebotes defensivos. As correlações negativas mais fortes foram encontradas para alto número de faltas cometidas, baixo número de rebotes ofensivos, arremessos de dois pontos perdidos e três pontos perdidos. Ibáñez et al. (2003), analisaram o campeonato mundial júnior de 1999 e encontraram quais variáveis de jogo diferenciaram os vencedores dos perdedores. Após analisar todas as 64 partidas foi encontrado que, conforme a diferença no placar da partida aumentava, mais indicadores se correlacionaram com os vencedores. Em partidas consideradas equilibradas (diferença final entre 12 a 24 pontos) as assistências, rebotes defensivos, sucesso nos dois pontos, lances livres e arremessos de três pontos não convertidos distinguiram as equipes. Nas partidas consideradas desequilibradas (placar final acima de 24 pontos) as faltas cometidas, rebotes defensivos e ofensivos, bloqueios, sucesso nos dois pontos e insucesso nos três pontos distinguiram os vencedores.

Analisando os contextos de gênero e nível competitivo, Sampaio, Godoy e Feu (2004) buscaram as variáveis de jogo que indicassem um bom desempenho nas partidas, analisando os campeonatos mundiais de ambos os sexos, nos níveis júnior e adulto, ocorridos entre 1999 e 2002. As partidas masculinas diferiram das femininas na alta porcentagem dos bloqueios, baixo percentual de desarmes e poucos arremessos de dois pontos não sendo convertidos em cesta. As partidas juniores diferiram das adultas pelo baixo percentual de assistências e um alto percentual de turnovers. No basquetebol Brasileiro, Junior (2004) buscou variáveis que distinguissem os vencedores de acordo com o local da partida. Observando 606 partidas do campeonato Paulista de basquetebol, encontrou que 62\% das vitórias foram de mandantes, diferindo em arremessos, eficiência dos arremessos, rebotes, desarmes e assistências. Com as equipes vencedoras demonstrando um predomínio em todas as variáveis analisadas, independente do local, com exceção para os 
rebotes ofensivos. Sampaio et al. (2006) analisaram as estatísticas de jogo que melhor distinguisse os armadores, laterais e pivôs em partidas de playoff da liga Americana, liga Espanhola e Portuguesa. Em Portugal, considerado de menor nível técnico, pivôs e armadores são diferenciados principalmente pelas tarefas de rebotes defensivos e bloqueios de arremesso, além do baixo aproveitamento nas bolas de três pontos. $\mathrm{Na}$ Espanha, liga considerada intermediária, os armadores se destacam pelas ações ofensivas como as assistências, maior ocorrência das ações de três pontos convertidos e perdidos além do baixo índice de rebotes ofensivos. Nos Estados Unidos, liga considerada de alto nível, os armadores e pivôs são distintos pelas tarefas ofensivas dos rebotes ofensivos, assistências e arremessos de três pontos desperdiçados.

A Espanha é um grande polo nas pesquisas relacionadas à análise de jogo no basquetebol nas últimas décadas, com estudos e autores mapeando e conhecendo cada vez mais os diferentes contextos de jogo do país. Ibáñez et al. (2008), buscando estatísticas de jogo que indicassem o sucesso durante a temporada da segunda divisão de basquetebol da Espanha, observaram 870 partidas de 6 temporadas do campeonato. Encontraram que as equipes que se classificam para as partidas eliminatórias apresentam um melhor desempenho nas variáveis: lances livres, rebotes defensivos, assistências, desarmes, bloqueios de arremessos, menos faltas cometidas e eficácia ofensiva (Pontuação obtida dividida pela quantidade de posses de bola), além de cometer menos faltas em comparação com as equipes que não se classificam. Na fase ofensiva a assistência foi a variável que apresentou maior relevância para diferenciar os classificados, na fase defensiva o rebote defensivo teve a maior relevância para a diferenciação das equipes.

Buscando quais estatísticas de jogo seriam relevantes nos momentos mais instáveis das partidas, Navarro et al. (2009) analisaram 41 situações de jogo críticas (situações dos cinco minutos finais do tempo regular com uma diferença menor que seis pontos ou prorrogações) da edição 2007/2008 da liga Espanhola. Foi encontrado que o sucesso nos lances livres e obter mais rebotes defensivos demonstraram ser as estatísticas mais relevantes para a vitória nesses momentos cruciais das partidas.

No campeonato Europeu de seleções da edição de 2007, Csataljay et al. (2009), após observarem 54 partidas identificaram que as principais estatísticas que 
diferem os vencedores em partidas tratadas como equilibradas (diferença no placar final entre um e nove pontos) foram os arremessos de três pontos, os lances livres e o rebote defensivo. Lorenzo et al. (2010), analisaram 122 partidas do campeonato Europeu sub 16 de basquetebol, nas edições de 2004 e 2005, buscando encontrar quais as estatísticas do jogo que melhor diferissem os vencedores. Em partidas consideradas acirradas (diferença final menor que nove pontos no placar) as variáveis de maior relevância foram os erros e as assistências. Em partidas equilibradas (diferença final entre 10 e 29 pontos no placar) as variáveis em destaque foram o sucesso nos arremessos de dois pontos e os rebotes defensivos. Nas partidas consideradas desbalanceadas (placar final acima de 30 pontos) a variável arremesso de dois pontos convertido diferenciou as equipes.

Sampaio, Drinkwater e Leite (2010) buscaram encontrar diferenças no desempenho dos jogadores durante a temporada relacionando o tempo de atuação e qualidade da equipe no campeonato. Observaram 198 jogadores da liga Espanhola de basquetebol da temporada de 2007/2008, analisando fatores relevantes da atuação dos jogadores como: arremessos, passes, erros e rebotes. Com relação a qualidade das equipes, os jogadores de equipes mais fortes apresentam superioridade nas ações de passes e arremessos de dois pontos, enquanto os jogadores das equipes mais fracas apresentam baixo desempenho nos rebotes defensivos. A variável dos erros foi a mais importante para determinar o impacto dos jogadores no campeonato, com os jogadores de maior importância cometendo menos erros e jogando mais tempo, enquanto os jogadores de menor relevância cometeram mais erros e apresentaram menor tempo de atuação nas partidas. Na Liga americana Mikołajec, Maszczyk e Zając (2013), observando 8 temporadas, identificaram que os indicadores de performance que mais aproximam o sucesso durante todo 0 campeonato são: alto aproveitamento de vitórias, eficiência ofensiva, alta pontuação no terceiro quarto, aproveitamento de vitórias em partidas considerados equilibrados, faltas e desarmes.

Com o intuito de encontrar os indicadores que melhor diferenciassem os vencedores na fase classificatória e eliminatória (quais fases) da liga Espanhola de basquetebol, García et al. (2013) analisaram 323 partidas da edição de 2007/2008 do torneio. Foi encontrado que, em partidas da fase regular consideradas balanceados (diferença final da partida menor ou igual a 12 pontos), os times vencedores obtiveram 
uma melhor performance em assistências, rebotes defensivos e arremessos de dois pontos convertidos. Nas partidas eliminatórias, os rebotes defensivos e os arremessos de dois pontos convertidos foram determinantes para os vencedores. Em partidas desbalanceadas (diferença final da partida entre 13 e 28 pontos) na fase regular, a variável assistência foi a única significativa para os vencedores, enquanto nas partidas eliminatórias, os rebotes defensivos e os arremessos de três pontos convertidos diferem os vencedores em partidas finais do campeonato. Buscando encontrar as ações que determinassem o vencedor de acordo com o local e a diferença final no placar, García et al. (2014) analisaram 306 partidas da liga Espanhola de basquetebol de 2007/2008. De tal maneira, em vitórias das equipes mandantes em partidas balanceadas (diferença final entre um e 12 pontos), as assistências, sucesso nos arremessos de dois pontos e rebotes defensivos foram os indicadores significativos. Em vitórias dos mandantes com partidas desbalanceadas (diferença final de 13 a 28 pontos), a variável assistência foi o parâmetro essencial. Nas vitórias das equipes visitantes, em partidas balanceadas, as assistências e os desarmes são as ações de maior relevância. Em vitórias das equipes visitantes com partidas desbalanceadas, as assistências e a conversão dos arremessos de três pontos foram determinantes.

Na liga Brasileira de basquetebol Prochnow et al. (2017) analisaram os indicadores técnicos que diferenciaram as equipes vencedoras em sete temporadas. Foi constatado que rebotes defensivos e assistências diferenciam os vencedores em todas as edições do campeonato, além de que, em algumas edições, os arremessos de dois pontos e três pontos diferem os vencedores. Analisando os cinco campeonatos continentais de basquetebol do ano de 2015 Ibáñez et al. (2018) identificaram quais indicadores de performance melhor caracterizavam o basquetebol jogado em cada região. Foram analisadas 213 partidas e os resultados demonstraram que existiu diferença no perfil das equipes de cada campeonato. Dentre todos os indicadores de performance analisados, apenas as ações de três pontos convertidos e bloqueios de arremesso não apresentaram diferença significativa no perfil das competições, sendo que o indicador de performance de assistência demonstrou ser o de maior efeito neste comparativo. Foi encontrado que o basquetebol jogado no campeonato Asiático é considerado mais rápido devido ao seu alto volume de posses de bola. Também foi encontrado na Ásia o maior diferencial na pontuação final entre as equipes. As partidas analisadas no campeonato das Américas apresentaram o 
maior volume de pontuação. O campeonato Europeu foi o campeonato onde foram encontradas mais assistências e o penúltimo no comparativo dos erros, atrás apenas do continente da Oceania. Os campeonatos que apresentaram maiores similaridades foram os campeonatos Americano e Asiático enquanto o campeonato Europeu foi aquele que apresentou a maior diferença quando comparado com o continente Africano.

Buscando compreender a dinâmica vigente na liga de basquetebol da Espanha, Gómez et al. (2020) analisaram a evolução dos indicadores de performance pelo período de oito temporadas. Foram analisadas 2426 partidas de temporada regular entre a edição de 2009-2010 até a edição 2016-2017. Os resultados demonstraram que os indicadores de lance livre, rebotes, faltas, bloqueios de arremesso, desarmes e erros apresentaram estabilidade durante o período analisado. Os indicadores de arremessos de dois pontos (convertidos e perdidos) sofreram decréscimo. As assistências, arremessos de três pontos (convertidos e perdidos) apresentaram aumento demonstrando uma tendência de modificação, mesmo que mínima, na dinâmica das partidas. Giovanini et al. (2021), buscando encontrar os indicadores que determinassem os vencedores na fase regular e eliminatória da liga Brasileira de basquetebol, analisaram 1271 partidas das edições de 2014 a 2019 do torneio. Foi encontrado que na fase regular em partidas acirradas (um a sete pontos de diferença no placar final) os rebotes defensivos foram determinantes para as vitórias. Em partidas balanceadas (8 a 19 pontos de diferença no placar final), os rebotes defensivos, assistências e aproveitamento de arremessos de três pontos foram relevantes para a vitória. Nas partidas desbalanceadas (mais de 20 pontos de diferença no placar final) os indicadores de assistências, arremessos de três pontos convertidos, rebotes defensivos, aproveitamento nos arremessos de três e dois pontos foram aqueles que demonstraram ser decisivos para as vitórias. Nas partidas eliminatórias acirradas, os rebotes defensivos e o aproveitamento nos arremessos de três pontos foram relevantes para vencer a partida. Em partidas eliminatórias balanceadas, as assistências, rebotes defensivos e aproveitamento nos arremessos de dois pontos foram significativos. Em partidas eliminatórias desbalanceadas, apenas as assistências demonstraram relevância para as vitórias. 


\section{MÉTODO}

Foi utilizado como método de abordagem científica a observação sistemática não participante do contexto de jogo. Tal método consiste na observação de filmagem de partidas para coleta, análise e interpretação dos dados, de acordo com os propósitos específicos da investigação idealizados pelo pesquisador (ANGUERA; MENDO, 2013). As partidas foram analisadas no software livre Kinovea v.0.8.15 e os dados anotados em planilha eletrônica.

Baseado no mais alto nível de seleções e um maior controle da qualidade de oposição (MARCELINO; MESQUITA; SAMPAIO, 2011), foram analisadas todas as 38 partidas disputadas pelas equipes masculinas nos Jogos Olímpicos Rio 2016. As filmagens foram obtidas a partir de buscas em sites com política de domínio público. Por se tratar de uma pesquisa envolvendo seres humanos, mesmo sem os identificar, esta pesquisa obteve aprovação do Comitê de Ética em Pesquisa da universidade sede dos autores (CAAE: 67387017.7.0000.5659 - Anexo 1). Todos os procedimentos e cuidados éticos foram garantidos.

\section{Protocolo de observação e classificação do processo ofensivo}

As partidas foram inicialmente observadas seguindo o protocolo de análise baseado nos indicadores de performance (HUGHES; BARTLETT, 2002) propostos nas tabelas 1 e 2. Tais indicadores foram referenciados com a ação final da equipe atacante, considerando se o ataque foi finalizado ao alvo ou não. A continuidade da posse de bola não foi considerada nesse primeiro momento. Logo, se a equipe conseguisse um rebote ofensivo ou, caso a bola saísse de quadra, tal ataque era considerado como terminado e um novo ataque iniciado com o retorno da bola em jogo. 
Tabela 1. Descrição das variáveis de ação dos ataques com finalização.

\section{Ataques terminados com finalização}

Aro ou tabela: Finalização que atinge 0 aro ou a tabela e não se converte em pontuação.

Arremesso para Fora: Finalização que não atinge qualquer parte do alvo e não se converte em pontuação.

Bloqueio da defesa: Finalização que é bloqueada por um adversário impossibilitando a bola de chegar ao alvo.

Cesta de 2 pontos: Cesta anotada por uma das equipes dentro da área de dois pontos.

Cesta de 3 pontos: Cesta anotada por uma das equipes fora da área de dois pontos.

Lance livre convertido: Cesta anotada por uma das equipes no ato do lance livre.

Lance livre perdido: Cesta não anotada por uma das equipes no ato do lance livre.

Tabela 2. Descrição das variáveis de ação dos ataques sem finalização.

\section{Ataques terminados sem finalização}

Desarme: Momento em que o defensor tira o domínio da posse de bola do atacante.

Erro de ataque: Caracterizam-se como erro, a perda da posse de bola pela equipe atacante para o adversário, como em um passe errado e/ou uma recepção ineficiente.

Falta defensiva: Interrupção da fase ofensiva pela realização de falta por um jogador da equipe defensora.

Falta ofensiva: Interrupção da fase ofensiva pela realização de falta por um jogador da equipe atacante. 
Interceptação do passe: Interrupção da trajetória da bola após o passe, realizada por um defensor entre dois jogadores atacantes, ou quando o defensor se antecipa ao destino da bola lançada em um ponto futuro.

Intervenção oficial: Interrupção da partida pela arbitragem, por fatores que podem atrapalhar a continuidade do jogo.

Violação: Interrupção da fase ofensiva pela violação das regras por um jogador da equipe atacante.

O processo ofensivo foi entendido como a somatória de todos os ataques realizados do início da posse da bola até sua troca. Tal qual Kubatko et al. (2007), a posse de bola seria o momento que a equipe consegue o controle da bola e finaliza no instante em que a equipe perde o controle da bola, deixando explicitado que após uma finalização com a equipe obtendo o rebote ofensivo, a posse de bola se mantém e, neste momento, se inicia um novo ataque.

Figura 1. Planilha de análise com os processos ofensivos marcados em vermelho.

\begin{tabular}{|c|c|c|c|c|c|c|c|c|c|}
\hline AÇÃO & \multirow[b]{2}{*}{$A / B$} & \multirow{2}{*}{\begin{tabular}{|r} 
AÇÄ́O \\
B \\
\end{tabular}} & \multirow[t]{2}{*}{ REBOTE } & \multirow[t]{2}{*}{ SETOR FINALI } & \multirow[t]{2}{*}{ P-E-V } & \multirow[t]{2}{*}{ ATAQUE INICI } & \multirow[t]{2}{*}{ ATAQUE FINAL } & \multirow{2}{*}{\begin{tabular}{|l|} 
DURAÇÃO ATA \\
\end{tabular}} & \multirow{2}{*}{$\begin{array}{l}\text { A USA } \\
\text { B SERVIA }\end{array}$} \\
\hline $\bar{A}$ & & & & & & & & & \\
\hline & B & $\mathrm{DE}$ & & & lv & 06:07 & 06:00 & $00: 07$ & \\
\hline \multirow[t]{3}{*}{ G2 } & A & & & 2PTD & $\mathrm{P}$ & 05:59 & $05: 55$ & $00: 04$ & \\
\hline & B & TR & \multirow[t]{2}{*}{ OFE } & 3PTF & $E$ & $05: 54$ & $05: 45$ & $00: 09$ & \\
\hline & $B$ & $\mathrm{G} 2$ & & 2PTD & E & $05: 44$ & $05: 43$ & $00: 01$ & \\
\hline TR & A & & \multirow[t]{3}{*}{ OFE } & 3PTF & P & $05: 40$ & $05: 16$ & $00: 24$ & \\
\hline FD & A & & & & P & $05: 15$ & 05:14 & $00: 01$ & \\
\hline \multirow[t]{2}{*}{ G2 } & A & & & 2PTD & P & $05: 14$ & $05: 13$ & $00: 01$ & \\
\hline & $B$ & $B L$ & DEF & 2PTD & $E$ & 05:08 & $04: 57$ & $00: 11$ & \\
\hline TR & A & & \multirow[t]{5}{*}{ OFE } & 2PTD & $E$ & $04: 55$ & $04: 51$ & $00: 04$ & \\
\hline$B L$ & A & & & 2PTD & $E$ & $04: 50$ & $04: 49$ & $00: 01$ & \\
\hline \multirow[t]{4}{*}{ ER } & $\mathrm{A}$ & 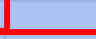 & & & E & $04: 49$ & $04: 45$ & $00: 04$ & \\
\hline & $B$ & $\mathrm{DE}$ & & & $E$ & $04: 44$ & $04: 27$ & $00: 17$ & \\
\hline & $B$ & FD & & & $E$ & $04: 27$ & $04: 21$ & $00: 06$ & \\
\hline & $B$ & TR & \multirow[t]{7}{*}{ DEF } & 3PTF & $E$ & $04: 21$ & $04: 15$ & $00: 06$ & \\
\hline \multirow[t]{2}{*}{ G2 } & A & & & 2PTD & $E$ & $04: 13$ & 04:06 & $00: 07$ & \\
\hline & B & G2 & & 2PTD & $P$ & 04:03 & $03: 47$ & $00: 16$ & \\
\hline \multirow[t]{4}{*}{$\mathrm{DE}$} & $\mathrm{A}$ & & & & $E$ & $03: 43$ & 03:34 & $00: 09$ & \\
\hline & $B$ & FD & & & $E$ & $03: 32$ & $03: 30$ & $00: 02$ & \\
\hline & B & G1 & & LL & E & $03: 30$ & $03: 30$ & $00: 00$ & \\
\hline & $B$ & G1 & & LL & V & $03: 30$ & $03: 30$ & $00: 00$ & \\
\hline
\end{tabular}

Em um terceiro momento, os processos ofensivos foram classificados a partir de sua pontuação gerada, dando forma aos indicadores de performance descritos na Tabela 3. 
Tabela 3. Descrição de classificação dos processos ofensivos

\begin{tabular}{|c|c|}
\hline Classificação & Final do processo ofensivo \\
\hline Não finalizado & Processo ofensivo encerrado sem arremessos. \\
\hline 0 ponto & $\begin{array}{l}\text { Processo ofensivo encerrado com arremesso, mas sem gerar } \\
\text { ponto. }\end{array}$ \\
\hline 1 ponto & Processo ofensivo finalizado gerando 1 ponto. \\
\hline 2 pontos & Processo ofensivo finalizado gerando 2 pontos. \\
\hline $3+$ pontos & Processo ofensivo finalizado gerando 3 pontos ou mais. \\
\hline
\end{tabular}

Foram analisadas variáveis contextuais para extrair informações relacionadas ao momento da finalização do ataque de cada equipe (Tabela 4).

Tabela 4 - Indicadores de variáveis contextuais.

\section{Duração do ataque}

Tempo de ataque: Duração do ataque desde o início da posse da bola até o momento de sua finalização.

\section{Estado do jogo}

Empatando: Equipe está empatando o jogo no momento da finalização do ataque.

Perdendo: Equipe está perdendo o jogo no momento da finalização do ataque.

Vencendo: Equipe está vencendo o jogo no momento da finalização do ataque.

\section{Finalização do ataque}

Com Finalização: Ataques finalizados com direção ao alvo.

Sem Finalização: Ataques que não foram finalizados ao alvo.

Posse de bola 
Mantida: Quando a equipe mantém a posse de bola ao final do ataque, continuando em fase ofensiva.

Trocada: Quando a equipe perde a posse de bola ao final do ataque, transitando para a fase defensiva.

\section{Rebotes}

Sem rebote: Após o arremesso nenhuma das equipes adquire a posse da bola diretamente, seja por pontuação, faltas ou outros aspectos.

Rebote Ofensivo: Após o arremesso, a bola toca o aro ou tabela e a equipe atacante mantém a posse da bola.

Rebote Defensivo: Após o arremesso, a bola toca o aro ou tabela e a equipe defensora mantém a posse da bola.

\section{Setor de finalização do ataque}

2 pontos dentro: Ataques finalizados na área de dois pontos, dentro da área restritiva.

2 pontos fora: Ataques finalizados na área de dois pontos, entre a área restritiva e a área de três pontos.

3 pontos: Ataques finalizados na área de três pontos.

Lance livre: Ataques finalizados no ato do lance livre.

\section{Confiabilidade}

Dois observadores, com experiência prévia na modalidade, realizaram 0 procedimento de confiabilidade. Eles passaram por um processo de aprendizagem do instrumento para a uniformização dos critérios (concordância por consenso) e consequente diminuição dos riscos de observação (ANGUERA, 1999; ANGUERA; MENDO, 2013). Nesta etapa, um observador (aluno de graduação) foi treinado por um observador experiente (treinador de basquetebol) a utilizar o protocolo de análise para a coleta dos indicadores de performance. $O$ treinamento consistiu em aplicações práticas do registro de dados, por meio do preenchimento do protocolo criado, em 
partidas de campeonatos anteriores, preservando a amostra do estudo. As medidas de confiabilidade intraobservador e interobservador foram testadas pelo índice Kappa de Cohen e ICC contempladas com a análise de 8 partidas, o que representa mais de 20\% da amostra (FLEISS; LEVIN; PAIK, 2003; LANDIS; KOCH, 1977). Foi verificada a consistência das análises do próprio analisador (fidedignidade) e na comparação dos observadores (objetividade) em um intervalo de 15 dias (O'DONOGHUE, 2010; THOMAS; NELSON; SILVERMAN, 2012). Os resultados dos valores inter e intraobservadores do teste Kappa (tabela 5) variaram de 0,958 a 0,996, demonstrando uma concordância quase perfeita (VIERA; GARRETT, 2005). Devido a categoria "Duração do ataque" se tratar de uma variável numérica foi utilizado o teste de índice ICC. O resultado dos valores inter e intraobservadores da categoria tempo variaram de 0,986 a 0,997, demonstrando uma concordância excelente (CICCHETTI, 1994).

Tabela 5. Valores obtidos na comparação interavaliadores (fidedignidade) e intra-avaliadores (objetividade).

\begin{tabular}{lccc}
\hline \multicolumn{1}{c}{ Variáveis } & Interavaliadores & Intra-avaliador A & Intra-avaliador B \\
\hline Equipe & 0,983 & 0,989 & 0,987 \\
Ação & 0,958 & 0,977 & 0,973 \\
Rebotes & 0,959 & 0,989 & 0,986 \\
Local & 0,959 & 0,982 & 0,978 \\
Estado do jogo & 0,970 & 0,985 & 0,979 \\
\hline
\end{tabular}

\section{Tratamento estatístico}

Após o processo de análise em cada partida do campeonato, as equipes foram separadas entre vencedoras e perdedoras em cada partida e identificadas as quatro equipes finalistas (superiores) das demais equipes (inferiores). Foi utilizado o teste qui-quadrado para testar a distribuição das classificações encontradas em âmbito global e em contextos específicos como: processos ofensivos terminados com finalização ao alvo ou não e processos ofensivos terminados com finalização gerando pontuação ou não. Para o comparativo entre as médias de ações e de classificações 
das equipes vencedoras ou perdedoras, foi utilizado o teste T pareado, sendo cada partida tratada como unidade de medida. Para comparar as médias de ações e de classificações das equipes superiores ( $1^{\circ}$ a $4^{\circ}$ colocadas) e inferiores $\left(^{\circ}\right.$ a $12^{\circ}$ colocadas) foi utilizado o teste $T$ não pareado, sendo utilizadas as equipes como unidade de medida para o teste. Para o teste qui-quadrado e para ambos os testes $\mathrm{T}$ o nível de significância foi fixado em $p<0,05$. 


\section{RESULTADOS}

Foi encontrada diferença significativa na distribuição da classificação dos processos ofensivos $\left(X^{2}(4)=1738,1 ; p<0,001\right)$. Os processos ofensivos classificados como 2 pontos $(32,8 \%)$ e 0 ponto $(31,8 \%)$ foram os mais recorrentes, seguidos pelo Não finalizado (18,7\%), 3+ pontos (12,7\%) e 1 ponto $(4,0 \%)$.

Também foi encontrada uma alta incidência de processos ofensivos que terminaram com finalização ao alvo (81,3\%), com diferença significativa em relação aos processos não finalizados ao alvo $\left(X^{2}(1)=2221,5 ; p<0,001\right)$. Entre os processos ofensivos finalizados ao alvo, houve, de maneira significativa $\left(X^{2}(1)=219,5\right.$; $p<$ 0,001), uma maior chance de gerar alguma pontuação $(60,9 \%)$.

Quando comparado a classificação dos processos ofensivos conforme o resultado da partida, foi encontrado que as equipes vencedoras apresentam, de maneira significativa, mais classificações de 2 pontos $(T(37)=-3,161 ; p=0,003)$ e de $3+$ pontos $(T(37)=-4,301 ; p<0,001)$, enquanto as equipes perdedoras apresentaram mais classificações de 0 ponto $(T(37)=4,046 ; p<0,001)$ (Figura 2A).

Figura 2. Comparação entre vencedores e perdedores $(A)$ e entre equipes superiores e inferiores $(B)$ em relação à classificação dos resultados dos processos ofensivos.

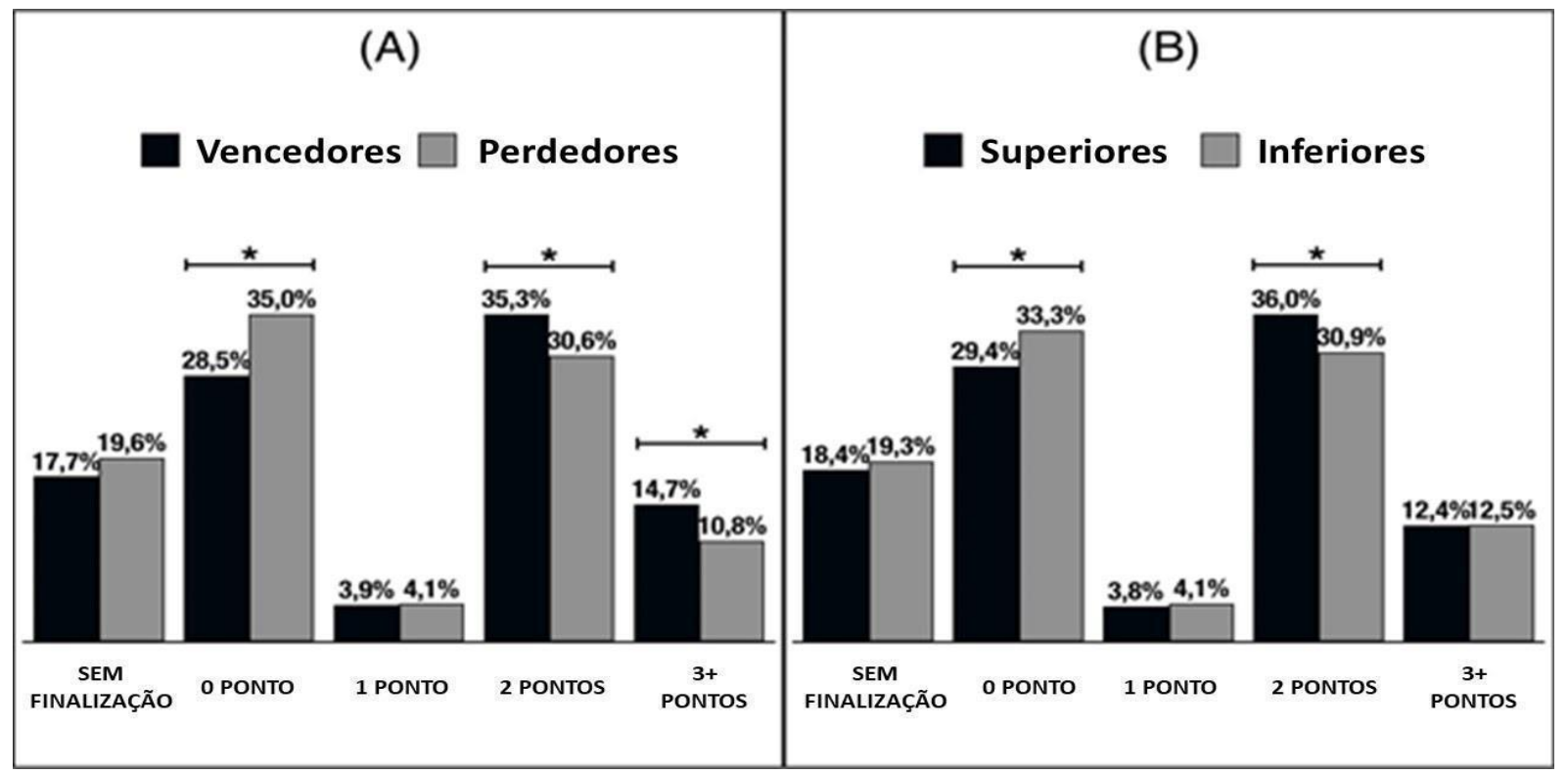

* diferença significativa $(p<0,05)$. 
$\mathrm{Na}$ comparação entre o nível das equipes, foi observado, também com diferença significativa, que as equipes inferiores tem maior incidência de processos ofensivos classificados como 0 ponto $(T(10)=-2,296 ; p=0,025)$, enquanto as equipes superiores apresentam superioridade nos processos classificados como 2 pontos ( $T$ $(10)=2,937 ; p=0,008)$ (Figura 2B).

As variáveis contextuais foram analisadas e suas médias apresentadas na tabela 6. Com relação aos rebotes, foi encontrada diferença significativa nas partidas para todas as categorias analisadas. Os perdedores conseguiram mais rebotes defensivos ( $T(37)=3,561 ; p=0,001$ ), os vencedores obtiveram mais rebotes ofensivos $(T(37)=-2,257 ; p=0,030)$ e ataques sem rebote $(T(37)=-3,114 ; p=$ $0,004)$. No campeonato apenas as situações sem rebote apresentaram diferença significativa ( $T(37)=2,408 ; p=0,019$ ) com as equipes superiores obtendo valores mais altos. Quanto ao local da finalização dos ataques, não houve diferença significativa na análise das partidas, quanto ao nível das equipes, os ataques de 2 pontos próximos da cesta apresentaram significância $(T(74)=2,492 ; p=0,015)$, com as equipes superiores finalizando mais ataques nesta situação. $O$ estado do jogo das partidas demonstra diferença significativa nas três categorias analisadas, com altos valores para situações vencendo para os vencedores e altos valores para situações perdendo para os perdedores. No campeonato foi encontrada diferença significativa nas categorias inferiores/perdendo $(T(74)=-3,267 ; p=0,002)$ e superiores/vencendo $(\mathrm{T}(74)=3,582 ; \mathrm{p}=0,001)$, demonstrando um cenário semelhante ao das partidas. $\mathrm{Na}$ análise da duração dos ataques, não foi encontrada diferença entre vencedores e perdedores. No nível das equipes, as superiores apresentam ataques mais rápidos que as inferiores $(T(74)=-2,808 ; p=0,006)$. 
Tabela 6. Resultados encontrados dos rebotes, local do ataque, estado do jogo e duração dos ataques.

\begin{tabular}{|c|c|c|c|c|c|c|}
\hline \multirow[b]{2}{*}{ Rebote } & \multicolumn{3}{|c|}{ Resultado da partida } & \multicolumn{3}{|c|}{ Nível da equipe } \\
\hline & Vencedor & Perdedor & $\begin{array}{l}\text { Valor } \\
\text { de } p\end{array}$ & Superior & Inferior & $\begin{array}{l}\text { Valor } \\
\text { de } p\end{array}$ \\
\hline Sem rebote & $96,8 \pm 10,4$ & $89,9 \pm 11,9$ & $0,004^{*}$ & $97,0 \pm 12,0$ & $90,7 \pm 10,7$ & $0,019^{\star}$ \\
\hline Rebote defensivo & $18,4 \pm 5,1$ & $22,2 \pm 5,2$ & $0,001^{*}$ & $19,0 \pm 5,2$ & $21,2 \pm 5$ & 0,068 \\
\hline Rebote ofensivo & $7,9 \pm 3,5$ & $6,3 \pm 2,8$ & $0,030^{*}$ & $7,9 \pm 3,7$ & $6,5 \pm 2,8$ & 0,079 \\
\hline \multicolumn{7}{|l|}{ Local do ataque } \\
\hline Sem finalização & $37,2 \pm 6,5$ & $37,8 \pm 6,5$ & 0,600 & $37,0 \pm 6,3$ & $37,8 \pm 6,7$ & 0,634 \\
\hline 2 pontos dentro & $31,6 \pm 5,8$ & $29,3 \pm 6,1$ & 0,099 & $32,4 \pm 5,6$ & $29,0 \pm 5,7$ & $0,015^{\star}$ \\
\hline 2 pontos fora & $8,2 \pm 3,1$ & $9,4 \pm 3,4$ & 0,119 & $8,0 \pm 3,0$ & $9,3 \pm 3,4$ & 0,101 \\
\hline 3 pontos & $24,4 \pm 6,6$ & $22,5 \pm 6,0$ & 0,162 & $24,6 \pm 5,7$ & $22,6 \pm 6,7$ & 0,179 \\
\hline Lance livre & $21,8 \pm 7,0$ & $19,2 \pm 7,4$ & 0,083 & $21,6 \pm 7,9$ & $19,7 \pm 6,9$ & 0,256 \\
\hline \multicolumn{7}{|l|}{ Estado do jogo } \\
\hline Empatando & $7,2 \pm 4,5$ & $5,9 \pm 4,5$ & $0,018^{\star}$ & $7,0 \pm 6,1$ & $6,1 \pm 4,0$ & 0,485 \\
\hline Perdendo & $22,5 \pm 26,7$ & $\begin{array}{c}95,47 \pm 27 \\
1\end{array}$ & $0,000^{\star}$ & $40,1 \pm 44,3$ & $72,6 \pm 41,6$ & $0,002^{*}$ \\
\hline Vencendo & $93,5 \pm 31,2$ & $17,0 \pm 25,5$ & $0,000^{*}$ & $76,6 \pm 47,5$ & $9,7 \pm 42,0$ & $0,001^{*}$ \\
\hline \multicolumn{7}{|c|}{ Duração dos ataques } \\
\hline Tempo de ataque & $8,5 \pm 1,2$ & $9,0 \pm 1,1$ & 0,128 & $8,3 \pm 1,1$ & $9,0 \pm 1,1$ & $0,006^{*}$ \\
\hline
\end{tabular}

Quanto à média de indicadores de performance por partidas (Tabela 7), encontramos que os ataques de Cesta de 2 pontos $(T(37)=-2,550 ; p=0,015)$, Cesta de 3 pontos $(T(37)=-3,778 ; p=0,001)$ e Lance livre convertido $(T(37)=-2,384 ; p=$ $0,022)$ apresentaram diferença significativa, com os vencedores obtendo melhores resultados. No comparativo do nível das equipes, apenas os ataques de Cesta de 2 pontos demonstraram diferença significativa $(T(74)=2,705 ; p=0,008)$, com as equipes superiores obtendo melhor resultado. 
Tabela 7. Resultados das ações encontradas por ataque.

\begin{tabular}{|c|c|c|c|c|c|}
\hline \multirow[b]{2}{*}{ Resultado do ataque } & \multicolumn{2}{|c|}{ Resultado da partida } & \multicolumn{3}{|c|}{ Nível da equipe } \\
\hline & Vencedor Perdedor & $\begin{array}{l}\text { Valor } \\
\text { de } p\end{array}$ & Superior & Inferior & $\begin{array}{c}\text { Valor } \\
\text { de } p\end{array}$ \\
\hline Aro ou tabela & $28,9 \pm 6,8 \quad 30,2 \pm 5,3$ & 0,364 & $30,0 \pm 6,8$ & $29 ; 1 \pm 56$ & 0,582 \\
\hline Cesta de 2 pontos & $22,3 \pm 4,9 \quad 19,5 \pm 4,2$ & $0,015^{\star}$ & $22,6 \pm 4,2$ & $19,7 \pm 4,7$ & $0,008^{*}$ \\
\hline Falta defensiva & $20,5 \pm 4,1 \quad 19,4 \pm 4,2$ & 0,204 & $20,7 \pm 4,4$ & $19,4 \pm 3,9$ & 0,170 \\
\hline Lance livre convertido & $16,9 \pm 6,0 \quad 14,1 \pm 5,5$ & $0,022^{*}$ & $16,4 \pm 6,5$ & $14,8 \pm 5,3$ & 0,242 \\
\hline Cesta de 3 pontos & $9,1 \pm 3,4 \quad 6,5 \pm 2,8$ & $0,001^{*}$ & $8,4 \pm 2,9$ & $7,4 \pm 3,6$ & 0,240 \\
\hline Interceptação do passe & $5,5 \pm 2,7 \quad 5,3 \pm 2,8$ & 0,796 & $5,2 \pm 2,4$ & $5,6 \pm 3,0$ & 0,531 \\
\hline Lance livre perdido & $5,0 \pm 2,0 \quad 5,1 \pm 2,9$ & 0,859 & $5,2 \pm 2,2$ & $4,9 \pm 2,7$ & 0,554 \\
\hline Desarme & $3,0 \pm 1,9 \quad 4,0 \pm 2,7$ & 0,118 & $3,1 \pm 2,3$ & $3,9 \pm 2,4$ & 0,168 \\
\hline Violação & $3,4 \pm 2,0 \quad 3,7 \pm 2,0$ & 0,485 & $3,2 \pm 1,9$ & $3,8 \pm 2,1$ & 0,144 \\
\hline Bloqueio da defesa & $2,6 \pm 1,5 \quad 3,4 \pm 2,1$ & 0,052 & $3,0 \pm 1,9$ & $3,0 \pm 1,9$ & 0,904 \\
\hline Erro de ataque & $3,0 \pm 1,8 \quad 3,4 \pm 1,7$ & 0,341 & $3,2 \pm 1,6$ & $3,2 \pm 1,9$ & 0,821 \\
\hline Falta ofensiva & $1,6 \pm 1,2 \quad 1,8 \pm 1,2$ & 0,387 & $1,7 \pm 1,3$ & $1,8 \pm 1,1$ & 0,681 \\
\hline Arremesso para Fora & $1,3 \pm 1,5 \quad 1,6 \pm 1,2$ & 0,311 & $1,2 \pm 1,6$ & $1,6 \pm 1,7$ & 0,220 \\
\hline Intervenção oficial & $0,08 \pm 0,3 \quad 0,16 \pm 0,4$ & 0,262 & $0,1 \pm 0,3$ & $0,1 \pm 0,3$ & 0,882 \\
\hline
\end{tabular}

${ }^{*}$ diferença significativa $(p<0,05)$ 


\section{DISCUSSÃO}

O objetivo do presente estudo foi compreender o processo de auto-organização do jogo de basquetebol por meio de uma classificação baseada no final dos processos ofensivos. Nossos achados revelaram que a finalização ao alvo demonstrou ser um balizador para que o sistema se auto-organize. Tal dinâmica é comprovada ao observarmos que $81,3 \%$ dos processos ofensivos analisados foram finalizados ao alvo. Tais características se devem pelas regras do jogo, que limitam o tempo de posse de bola e promovem restrições de contato físico para desarmar os adversários. Além disso, grande parte desses ataques finalizados terminam em pontuação $(60,9 \%)$, sendo os processos ofensivos de 2 pontos os de maior ocorrência $(66,5 \%)$ (Figura 3).

Figura 3. Processo de auto-organização do jogo de basquetebol baseado na classificação proposta no final dos processos ofensivos.

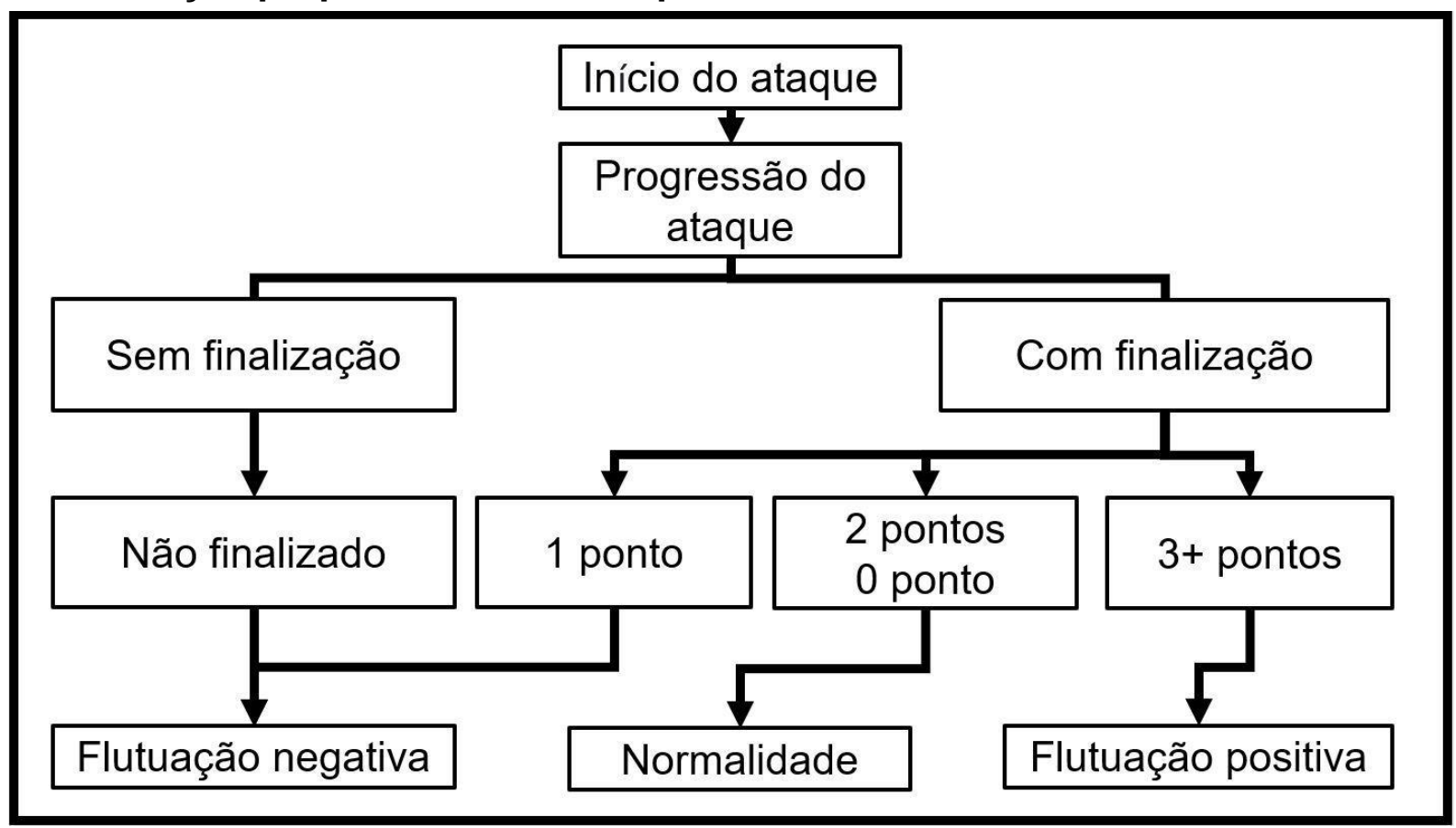

A auto-organização do jogo é entendida como o discernimento e a detecção de novos padrões assumidos por um sistema (CAPRA,1996), além da maneira pela qual as equipes se comportam sob variadas situações apresentadas durante as partidas (MENEZES, 2012). Desse modo, podemos entender que, no ambiente observado, os processos ofensivos que terminam nas classificações 2 pontos e 0 ponto podem ser 
considerados como uma normalidade do sistema do jogo basquetebol. Porém, como observado nos resultados, o fator relevante para diferenciar o sucesso das equipes foi a classificação 2 pontos. Além de observar que os processos ofensivos classificados como 3+ pontos apresentaram diferença significativa nas partidas, mas não apresentaram relevância quando observadas as equipes que têm maior êxito nas competições.

Levando em consideração que as flutuações são pequenas modificações que podem causar alterações na auto-organização do sistema do jogo, quer sejam negativas, como aquelas flutuações que buscam manter o sistema próximo de sua estabilidade; ou positivas, como aquelas que apresentam maior disparidade de sua estabilização (CAPRA,1996; MORATO; GOMES; ALMEIDA, 2012), nossos achados permitem tratar como flutuações no jogo de basquetebol, as situações nas quais as equipes: a) concluíram o processo ofensivo com uma finalização, porém conseguindo uma pontuação abaixo dos dois pontos esperados (um ponto). Tal momento pode ser considerado como uma flutuação negativa pois é uma perturbação na organização do sistema do jogo, mas ainda próximo de sua lógica, uma vez que houve finalização e a pontuação foi atingida; b) terminam o processo ofensivo sem gerar uma finalização (Não finalizado), o que promove uma flutuação positiva, pois tal processo não vai ao encontro do principal atrator para a dinâmica das partidas, que é a finalização ao alvo; c) e, ainda, um outro momento de flutuação encontrado, foi aquele no qual as equipes conseguem finalizar o processo ofensivo gerando três ou mais pontos (3+ pontos). Tal processo completa todas as etapas da auto-organização do jogo e gera uma pontuação acima da esperada pelo padrão. Esse processo foi considerado uma flutuação positiva, pois causa um desequilíbrio na partida, sendo um dos fatores que difere os vencedores e perdedores nas partidas.

$\mathrm{Na}$ literatura, diversos trabalhos relacionam indicadores de ação com 0 vencedor da partida no basquetebol (IBÁÑEZ et al., 2018). O fato dos processos ofensivos gerarem finalização e consequente pontuação, na maior parte das vezes, demonstra a extrema importância desse momento na dinâmica do jogo. Os lances livres convertidos demonstram atuação direta na classificação 1 Ponto, apresentando relevância para diferenciar os vencedores e perdedores nas partidas analisadas. Esta diferença significativa demonstra que mesmo com algum infortúnio durante a partida, existe uma extrema importância de sempre buscar finalizar o processo ofensivo 
gerando alguma pontuação. Nas partidas decisivas do campeonato europeu de clubes nas edições de 1992 até 2000, os lances livres convertidos apresentaram contribuição nas vitórias das equipes (TRNINIĆ; DIZDAR; LUKŠIĆ, 2002). Tais achados se mantiveram ao analisar o torneio continental de seleções Europeias na edição de 2007, os lances livres demonstraram ser uma variável de interesse para partidas com placares finalizados com menos de dez pontos de diferença (CSATALJAY et al., 2009). Os lances livres também demonstraram importância para a vitória na fase regular da liga Portuguesa, além de apresentarem relevância nas vitórias de visitantes em partidas eliminatórias (SAMPAIO; JANEIRA, 2003).

A cesta de dois pontos demonstra ser a ação mais importante do jogo de basquetebol. Ratificando a importância dos processos terminados com dois pontos, García et al. (2014), encontraram que as variáveis 2 pontos, rebote defensivo e assistência foram determinantes para vitória dos mandantes em partidas balanceadas na liga Espanhola de 2007/2008. As cestas de dois pontos auxiliam diretamente na composição da classificação mais recorrente no estudo (2 pontos).

A cesta de dois pontos é encontrada no estudo como a única variável de ação que apresenta diferença significativa nas partidas e no campeonato. A importância de tal ação é comprovada ao encontrarmos que existiu diferença significativa no local do ataque com relação ao nível das equipes. Estes resultados reforçam que, ao criar mais ações próximas da cesta, as equipes estão mais próximas de obter um bom desempenho no campeonato. Na liga Espanhola de basquetebol, analisando um período de 10 anos, Puente et al. (2015) demonstraram que em partidas de fase regular, a acurácia nos arremessos de dois pontos é uma das variáveis de maior associação com a vitória. No campeonato europeu de clubes de 2016-2017, os arremessos de dois pontos convertidos, arremessos de três pontos convertidos, desarmes e rebotes defensivos apresentaram grande influência nos modelos de análise propostos para definir as equipes vencedoras (ÇENE, 2018). Tais informações corroboram a ideia de que cumprir o ciclo de auto-organização de maneira positiva pelo maior período possível, além de aproximar a equipe da vitória também pode trazer maior estabilidade a longo prazo na competição. Nossos dados evidenciam essa questão ao demonstrarmos que as equipes vencedoras (nível partida) e superiores (nível competição) permanecem mais tempo vencendo suas partidas. 
As cestas de três pontos contribuem diretamente para as flutuações positivas. Demonstram grande impacto nas partidas, uma vez que a tendência das equipes é finalizar os processos ofensivos não pontuando ou obtendo dois pontos. A cada momento que é convertido um arremesso de três pontos ou situações de faltas acompanhadas de cesta com lance livre de bonificação convertido, a equipe adversária é colocada em um cenário que cumprir o ciclo lógico do jogo não modifica uma possível desvantagem. Se tal circunstância é apresentada na partida repetidas vezes, a auto-organização vigente pode ser modificada. A possível modificação da auto-organização ou uma vantagem no placar causada pelas cestas de três pontos, obrigando o adversário a arriscar mais na abordagem ofensiva. Neste contexto, as equipes perdedoras aumentam a agressividade no ataque por estarem ameaçadas podendo cometer erros cruciais ao buscar arremessos de três pontos de longa distância ou pressionados.

A ação de arremessar de três pontos é uma tendência. Comparando os diferentes campeonatos continentais de seleções, Ibáñez et al. (2018) encontraram que apenas as ações de três pontos convertidos e bloqueios de arremesso não apresentaram diferença significativa no perfil das competições. Isso demonstra que independente das particularidades de cada contexto, os arremessos e os bloqueios fazem parte da caracterização do jogo de seleções.

Na liga brasileira de basquetebol as cestas de três pontos são parte integral da dinâmica do jogo. Giovanini et al. (2021) encontraram que os arremessos de três pontos convertidos são relevantes nas vitórias em: partidas balanceadas, partidas desbalanceadas e nas partidas eliminatórias tratadas como acirradas. No basquete espanhol Gómez et al. (2020) analisaram a evolução dos indicadores de performance da liga Espanhola de basquetebol pelo período de oito anos. Foi encontrada uma diminuição dos arremessos de dois pontos e um aumento dos arremessos de três pontos e assistências, demonstrando que os arremessos mais longos estão sendo mais utilizados ao passar dos anos. Com as assistências em tendência de aumento é plausível acreditar que mais arremessos sem pressão estão sendo executados durante as partidas ao efetivar o uso de uma maior área no campo ofensivo. Entretanto, nossos resultados demonstram que as cestas de três pontos foram significativas apenas para diferenciar os vencedores das partidas, não sendo encontrado o mesmo efeito em relação ao campeonato. 
Com relação aos rebotes, as equipes vencedoras apresentaram mais situações sem rebote, além de conseguirem reter mais rebotes ofensivos, obtendo mais segundas chances para pontuar. No campeonato apenas a categoria sem rebote apresentou diferença significativa. Na literatura da análise de jogo no basquetebol encontramos que o rebote defensivo é recorrente nos estudos e está diretamente ligado à maneira que as equipes se auto-organizam, uma vez que representa o fim do processo ofensivo da equipe atacante, sem pontuação e sem uma segunda chance para finalização. Nas partidas dos Jogos Olímpicos de 2004 a 2016, um alto desempenho nos arremessos de quadra combinados com rebotes defensivos, elucidaram 93.2\% das vitórias nas partidas pelos modelos estatísticos propostos (LEICHT; GÓMEZ; WOODS, 2017). Analisando a edição de 2004/2005 da liga Espanhola de basquetebol em duas oportunidades Gómez et al. (2008a, 2008b), constatou que os rebotes defensivos são preponderantes para as vitórias. Independente das situações de placar e mando de partida. Outros dados relevantes foram encontrados em nossa pesquisa, o rebote ofensivo apresenta diferença significativa, demonstrando uma superioridade das equipes vencedoras em conseguirem mais segundas chances para pontuar. A situação da categoria sem rebote demonstra que as equipes vencedoras e superiores podem obter um aproveitamento melhor nos arremessos. Durante as partidas foram encontrados valores superiores e apresentaram diferença significativa em todos os arremessos convertidos, finalizando mais ataques sem a possibilidade de rebote por parte das equipes perdedoras. No campeonato também são encontrados valores superiores para todos os arremessos convertidos, porém apenas as cestas de dois pontos apresentaram diferença significativa.

Com relação ao estado do jogo observamos que poucas mudanças de liderança na pontuação ocorrem nos Jogos Olímpicos. As equipes vencedoras apresentam um volume muito maior de ações vencendo, as equipes perdedoras apresentam muitas ações perdendo e o empate é uma situação mínima durante as partidas. Este cenário se repete no campeonato com as equipes superiores também dominando as partidas e as equipes inferiores tendo ações com o placar adverso no maior período das partidas. Este fenômeno impacta diretamente no tempo de ataque das equipes. Courel et al. (2014), analisando 25 partidas eliminatórias da liga Americana de basquetebol de 2011 , encontraram que jogar em um ritmo mais rápido 
aumenta a possibilidade de pontuar. Equipes vencedoras se preparam para fazer ataques rápidos e contra ataques, enquanto as equipes perdedoras acabam fazendo ataques mais lentos, conseguindo apenas ataques mais posicionados. Também foi constatado que neste contexto, aumentar a intensidade nas partidas e diminuir a velocidade de jogo do adversário tem grande relevância para um resultado positivo. 


\section{CONCLUSÃO}

Este estudo apresenta uma interpretação do basquetebol com base em uma abordagem sistêmica, procurando entender a sua auto-organização. Buscando responder as perguntas norteadoras do estudo iniciamos identificando a normalidade do sistema-jogo nas partidas do contexto analisado. Os resultados apontam que existe uma prevalência de sucesso do ataque sobre a defesa e que os processos ofensivos finalizados ao alvo com classificações de 0 ponto e 2 pontos constroem a estabilidade do sistema do jogo. Com o intuito de descobrir as possíveis flutuações existentes no sistema-jogo foi encontrado que os processos classificados como 3+pontos, 1 ponto e Não finalizado foram considerados como flutuações do sistema jogo. Em relação a influência das flutuações no desempenho das equipes nas partidas e no campeonato encontramos que os processos classificados $3+$ pontos demonstraram ser um momento relevante das partidas, porém no campeonato tais momentos não demonstraram relevância significativa.

Tal ferramenta traz um diagnóstico de como o sistema do jogo se auto-organiza no ambiente em questão, um ambiente de seleções de elite, sendo necessárias pesquisas que analisem outros ambientes e competições para que estes contextos possam ser melhor compreendidos. A classificação proposta pode ser utilizada como uma ferramenta de análise durante as partidas, para avaliar como a equipe está se comportando, com base nos conceitos auto-organizacionais pré-estabelecidos para o contexto analisado. A classificação proposta também pode auxiliar no processo de treinamento, na busca de situações que reforcem o cumprimento do ciclo autoorganizacional dentro de cada contexto e auxilie os atletas a entenderem qual o comportamento do jogo que eles estão inseridos. 


\section{REFERÊNCIAS}

ÁLVAREZ, A. et al. Study of the defensive performance indicators in peak performance basketball. Revista de Psicología del Deporte, v. 18, n. 3, p. 379-384, 2009.

ANGUERA, M. T. Observación en deporte y conducta cinésico-motriz: aplicaciones. Edicions Universitat Barcelona, 1999.

ANGUERA, M. T.; MENDO, A. H. La metodología observacional en el ámbito del deporte [Observational methodology in sport sciences]. E-balonmano. com: Revista de Ciencias del Deporte, v. 9, n. 3, p. 135-160, 2013.

BARRAGÁN, R. M. N. Análisis cuantitativo y cualitativo de los momentos críticos en baloncesto $=$ Quantitative and qualitative analysis of the critical moments in basketball. 2015. Tese de Doutorado - Universidad Politécnica de Madrid, Madrid, 2015.

BAYER, C. O ensino dos desportos colectivos. Lisboa: Dinalivros, 1994.

CAPRA, F.; EICHEMBERG, N. R. A teia da vida: uma nova compreensão científica dos sistemas vivos. São Paulo: Cultrix, 2006.

ÇENE, E. What is the difference between a winning and a losing team: insights from Euroleague basketball. International Journal of Performance Analysis in Sport, v. 18, n. 1, p. 55-68, 2018.

CICCHETTI, D. V. Guidelines, criteria, and rules of thumb for evaluating normed and standardized assessment instruments in psychology. Psychological assessment, $\mathrm{v}$. 6, n. 4, p. 284, 1994.

COUREL, J. et al. The impact of match status on game rhythm in NBA basketball. In: Congress of the European College of Sport Science, 2014, Amsterdam.

CSATALJAY, G. et al. Performance indicators that distinguish winning and losing teams in basketball. International Journal of Performance Analysis in Sport, v. 9, n. 1, p. 60-66, 2009.

DE ROSE JUNIOR, D.; TRICOLI, V. Basquetebol: conceitos e abordagens gerais (org.). Basquetebol: uma visão integrada entre ciência e prática. Barueri: Manole, p. 123-143, 2005.

D'OTTAVIANO, I M. L.; BRESCIANI FILHO, E. Auto-organização e criação. MultiCiência, v. 3, p. 1-23, 2004.

FLEISS, J. L.; LEVIN, B.; PAIK, M. C. Statistical methods for rates and proportions. John Wiley \& Sons, 2013. 
GALATTI, L. R. et al. Campeonas del Mundo de Baloncesto: factores determinantes para el rendimiento de excelencia. Cuadernos de Psicología del Deporte, v. 15, n. 3, p. 187-192, 2015.

GARCíA, J. et al. Basketball Game-related statistics discriminating ACB league teams according to game location, game outcome and final score differences. International Journal of Performance Analysis in Sport, v. 14, n. 2, p. 443-452, 2014.

GARCÍA, J. et al. Identifying basketball performance indicators in regular season and playoff games. Journal of human kinetics, v. 36, n. 1, p. 161-168, 2013.

GIOVANINI, B. et al. Assessing the key game-related statistics in Brazilian professional basketball according to season phase and final score difference. International Journal of Performance Analysis in Sport, p. 1-11, 2021.

GÓMEZ, M. A. et al. Differences in game-related statistics of basketball performance by game location for men's winning and losing teams. Perceptual and motor skills, v. 106 , n. 1 , p. $43-50,2008$. (a)

GÓMEZ, M. A. et al. Game-related statistics that discriminated winning and losing teams from the Spanish men's professional basketball teams. Collegium antropologicum, v. 32, n. 2, p. 451-456, 2008. (b)

GÓMEZ, M. Á. et al. The Performance Evolution of Match Play Styles in the Spanish Professional Basketball League. Applied Sciences, v. 10, n. 20, p. 7056, 2020.

GÓMEZ, M. A.; EVANGELOS, T.; ALBERTO, L. Defensive systems in basketball ball possessions. International Journal of Performance Analysis in Sport, v. 6, n. 1, p. 98-107, 2006.

GREHAIGNE, J.F.; BOUTHIER, D.; DAVID, B. Dynamic-system analysis of opponent relationships in collective actions in soccer. Journal of sports sciences, v. 15, n. 2 , p. 137-149, 1997.

HUGHES, M. D.; BARTLETT, R. M. The use of performance indicators in performance analysis. Journal of sports sciences, v. 20, n. 10, p. 739-754, 2002.

HUGHES, M.; FRANKS, I. The essentials of performance analysis: an introduction. Routledge, 2007.

IBÁÑEZ, S. J. et al. Basketball game-related statistics that discriminate between teams' season-long success. European journal of sport science, v. 8, n. 6, p. 369372, 2008. 
IBÁÑNEZ, S. J. et al. Basketball without borders? Similarities and differences among Continental Basketball Championships. Revista Internacional de Ciencias del Deporte, v. 14, n. 51, p. 42-54, 2018.

IBÁÑEZ, S. J. et al. Game statistics discriminating the final outcome of junior world basketball championship matches (Portugal 1999). Journal of Human Movement Studies, v. 45, n. 1, p. 1-20, 2003.

JUNIOR, D. R. Statistical analysis of basketball performance indicators according to home/away games and winning and losing teams. Journal of Human Movement Studies, v. 47, p. 327-336, 2004.

KUBATKO, J. et al. A starting point for analyzing basketball statistics. Journal of Quantitative Analysis in Sports, v. 3, n. 3, 2007.

LANDIS, J. R.; KOCH, G. G. The measurement of observer agreement for categorical data. biometrics, p. 159-174, 1977.

LEICHT, A. S.; GÓMEZ, M. A.; WOODS, C. T. Explaining match outcome during the men's basketball tournament at the Olympic Games. Journal of Sports Science \& Medicine, v. 16, n. 4, p. 468, 2017.

LEONARDO, L.; SCAGLIA, A. J.; REVERDITO, R. S. O ensino dos esportes coletivos: metodologia pautada na família dos jogos. Motriz. Revista de Educação Física. UNESP, v. 15, n. 2, p. 236-246, 2009.

LORENZO, A. et al. Game related statistics which discriminate between winning and losing under-16 male basketball games. Journal of sports science \& medicine, v. 9, n. 4, p. 664, 2010.

MARCELINO, R.; MESQUITA, I.; SAMPAIO, J. Effects of quality of opposition and match status on technical and tactical performances in elite volleyball. Journal of sports sciences, v. 29, n. 7, p. 733-741, 2011.

MCGARRY, T. et al. Sport competition as a dynamical self-organizing system. Journal of sports sciences, v. 20, n. 10, p. 771-781, 2002.

MENEZES, R. P. Contribuições da concepção dos fenômenos complexos para o ensino dos esportes coletivos. Motriz: Revista de Educação Física, p. 34-41, 2012.

MENEZES, R. P.; MARQUES, R. F. R.; MORATO, M. P. Percepção de treinadores de andebol sobre as variáveis defensivas e ofensivas do jogo na categoria sub12. Motricidade, v. 12, n. 3, p. 06-19, 2016.

MENEZES, R. P.; MARQUES, R. F. R.; NUNOMURA, M. Especialização esportiva precoce e o ensino dos jogos coletivos de invasão. Movimento, v. 20, n. 1, p. 351373, 2014. 
MIKOŁAJEC, K.; MASZCZYK, A.; ZAJĄC, T. Game indicators determining sports performance in the NBA. Journal of human kinetics, v. 37, n. 1, p. 145-151, 2013.

MORATO, M. P.; GOMES, M. S. P.; ALMEIDA, J. J. G. D. The self-organizations processes of goalball. Revista Brasileira de Ciências do Esporte, v. 34, n. 3, p. 741760, 2012.

NAVARRO, R. M. et al. Analysis of critical moments in the league ACB 2007-08. Revista de Psicología del Deporte, v. 18, n. 3, p. 391-395, 2009.

O'DONOGHUE, P. Research methods for sports performance analysis. Routledge, 2010.

PASSOS, P.; ARAÚJO, D.; DAVIDS, K. Self-organization processes in field-invasion team sports. Sports Medicine, v. 43, n. 1, p. 1-7, 2013.

PERL, J. (2004). 1 MODELLING DYNAMIC SYSTEMS BASIC ASPECTS AND APPLICATION TO PERFORMANCE ANALYSIS.

PROCHNOW, R. A. et al. Análisis de indicadores técnicos que discriminan equipos ganadores y perdedores en el nuevo Baloncesto Brasil. SPORT TK-Revista EuroAmericana de Ciencias del Deporte, p. 207-212, 2017.

PUENTE, C. et al. Basketball performance indicators during the ACB regular season from 2003 to 2013. International Journal of Performance Analysis in Sport, v. 15, n. 3, p. 935-948, 2015.

REED, D.; HUGHES, M. An Exploration of Team Sport as a Dynamical System. International Journal of Performance Analysis in Sport, v. 6, n. 2, p. 114-125, 2006.

SAMPAIO, J. et al. Discriminant analysis of game-related statistics between basketball guards, forwards and centres in three professional leagues. European journal of sport science, v. 6, n. 3, p. 173-178, 2006.

SAMPAIO, J.; DRINKWATER, E. J.; LEITE, N. M. Effects of season period, team quality, and playing time on basketball players' game-related statistics. European Journal of Sport Science, v. 10, n. 2, p. 141-149, 2010.

SAMPAIO, J.; GODOY, S. I.; FEU, S. Discriminative power of basketball game-related statistics by level of competition and sex. Perceptual and motor Skills, v. 99, n. 3_suppl, p. 1231-1238, 2004.

SAMPAIO, J.; JANEIRA, M. Statistical analyses of basketball team performance: understanding teams' wins and losses according to a different index of ball possessions. International Journal of Performance Analysis in Sport, v. 3, n. 1, p. 40-49, 2003. 
THOMAS, J. R.; NELSON, J. K. Silverman. Métodos de Pesquisa em Atividade Física. Tradução: Ricardo Demétrio de Souza Petersen. 6 ed. ed Porto Alegre: Artmed Editora, 2012.

TRNINIĆ, S.; DIZDAR, D.; LUKŠIĆ, E. Differences between winning and defeated top quality basketball teams in final tournaments of European club championship. Collegium antropologicum, v. 26, n. 2, p. 521-531, 2002.

VIERA, A. J.; Garrett, J. M. Understanding interobserver agreement: the kappa statistic. Fam med, v. 37, n. 5, p. 360-363, 2005. 


\section{ANEXO 1}

USP - ESCOLA DE EDUCAÇÃO
FISICA E ESPORTE DE
RIBEIRÃO PRETO DA USP

\section{PARECER CONSUBSTANCIADO DO CEP}

\section{DADOS DO PROJETO DE PESQUISA}

Título da Pesquisa: AUTO-ORGANIZAÇÃO DOS JOGOS ESPORTIVOS COLETIVOS DE INVASÃO: DESCRIÇÃ̃O DOS PADRÖES E COMPARAÇÕES ENTRE SEXOS

Pesquisador: MÁRCIO PEREIRA MORATO

Área Temática:

Versão: 1

CAAE: 67387017.7 .0000 .5659

Instituição Proponente: UNIVERSIDADE DE SAO PAULO

Patrocinador Principal: Financiamento Próprio

\section{DADOS DO PARECER}

Número do Parecer: 2.095 .778

\section{Apresentação do Projeto:}

PROJETO: Auto-organização dos jogos esportivos coletivos de invasão: descrição dos padrões e comparações entre os sexos.

PESQUISADOR RESPONSÁVEL: Marcio Pereira Morato

INSTITUIÇÃO RESPONSÁVEL: Escola de Educação Física e Esporte de Ribeirão Preto da Universidade de São Paulo

CEP de origem: Comitê de Ética em Pesquisa com Seres Humanos da Escola de Educação Fisica e Esportes de Ribeirão Preto da Universidade de São Paulo.

ÁREA DE ESTUDO: Ciências Humanas

APRESENTAÇÃO DO PROJETO: o presente projeto pretende identificar o ciclo de auto-organização de diferentes jogos esportivos coletivos de invasão, a partir da observação sistemática não participante de partidas de jogos de diferentes modalidades. A amostra corresponde a vídeos de domínio publico de partidas de ambos os sexos. Busca-se com a realização desta pesquisa atingir a compreensão do cicio auto -organizacional de cada $\mathrm{JECl}$, para contribuir com a especificidade do treinamento de cada esporte.

Endereço: Avenida Bandeirantes, 3900

Bairro: VILA MONTE ALEGRE

UF: SP Município: RIBEIRAO PRETO

Telefone: (16)3315-0494

CEP: $14.040-907$

E-mail: cepeo@usp.br 


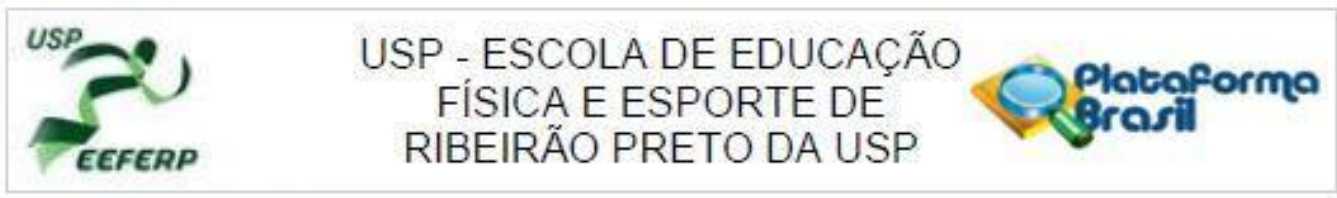

Contruaç50 do Parecer. 2.095 .778

Objetivo da Pesquisa:

Objetivo geral: identificar o ciclo auto-organizacional de diferentes $\mathrm{JECl}$.

Objetivos especificos: (i) mapear os aspectos que definem a auto-organizacao de cada $\mathrm{JECl}$; (ii) comparar a auto-organizacao de cada JECl entre sexos; (iii) comparar e discutir a auto-organizacao entre os JECl.

Avaliação dos Riscos e Beneficios:

Riscos

"por se tratar de observacao de filmagens com foco nas situacoes e caracteristicas das partidas de JECle nao especificamente nos atletas, que nao serao identificados, o risco potencial para os participantes e minimo*.

Beneficios

"Estudos dessa natureza possibilitam a configuracao de modelos de equipes e jogadores; a identificacao de padroes eficazes associados a qualidade do jogo e a obtencao de resultados positivos; a planificacao e organizacao do treino pelo desenvolvimento de metodos mais especificos e transferiveis ao contexto competitivo; a avaliacao e regulacao da aprendizagem para melhorar o desempenho dos jogadores; e a indicacao de tendencias evolutivas nas diferentes modalidades".

Comentários e Considerações sobre a Pesquisa:

O projeto de pesquisa está apresentado de forma clara e com fundamentação teórica e metodológica adequadas, sustentado por revisão da literatura atual. O tema é relevante e pertinente à área da Educação Física, é exequível, considerando a complexidade e o cronograma de trabalho.Solicita e justifica a dispensa do uso do Termo de Consentimento Livre e Esclarecido

Consideraçöes sobre os Termos de apresentação obrigatória:

Os termos obrigatórios estão adequados e foram devidamente apresentados.

Recomendações:

Não há.

Conclusões ou Pendências e Lista de Inadequações:

Não há

Consideraçôes Finais a critério do CEP:

O projeto encontra-se APROVADO para execução. Pedimos atenção aos seguintes itens:

1) De acordo com a Resolução CNS n. ${ }^{\circ} 466 / 2012$, o pesquisador deverá apresentar relatórios

Endereço: Avenida Bandeirantes, 3900

Bairro: VLA MONTE ALEGRE

UF: SP MUnicipio: RIBEIRAO PRETO

Telefone: (16)3315-0494

CEP: $14.040-807$ 


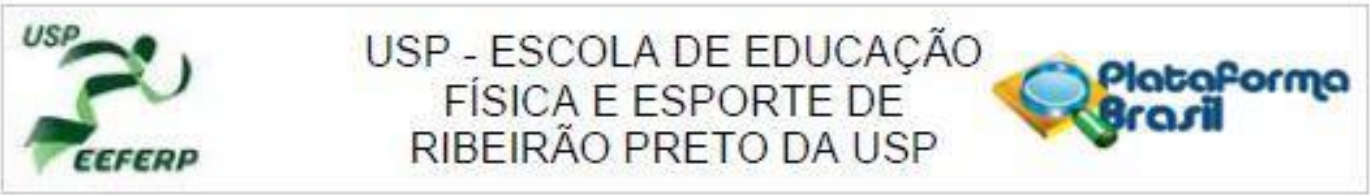

Contunuaç5̆ do Parecer. 2.095 .778

semestrais (parciais e final, em função da duração da pesquisa);

2) Eventuais emendas (modificações) ao protocolo devem ser apresentadas, com justificativa, ao CEP de forma clara e sucinta, identificando a parte do protocolo a ser modificada. Neste caso, o pesquisador deve aguardar nova aprovação do CEP para realizar os procedimentos de acordo com as mudanças solicitadas;

3) Sobre o TCLE: caso o termo tenha DUAS páginas ou mais, lembramos que no momento da sua assinatura, tanto o participante da pesquisa (ou seu representante legal) quanto o pesquisador responsável deverão RUBRICAR todas as folhas, colocando as assinaturas na última página;

4) Caso haja instituição(ões) coparticipante(s) no projeto, atender a solicitação da carta $n .^{\circ}$ $0212 /$ CONEPICNS, de 21 de outubro de 2010;

5) GARANTIR QUE NOS MOMENTOS DE ATIVIDADE FISICA SEMPRE HAJA PELO MENOS UM MEMBRO DA EQUIPE DE PESQUISA APTO A PRESTAR OS SOCORROS DE URGÊNCIA, INCLUSIVE MASSAGEM CARDIACA E USO DO DEA, CASO NECESSÁRIO

Este parecer foi elaborado baseado nos documentos abaixo relacionados:

\begin{tabular}{|c|c|c|c|c|}
\hline Tipo Documento & Arquivo & Postagem & Autor & Situação \\
\hline $\begin{array}{l}\text { Informações Básicas } \\
\text { do Projeto }\end{array}$ & $\begin{array}{l}\text { PB_INFORMAÇŌES_BÁSICAS_DO_P } \\
\text { ROJETO_901757.pdf }\end{array}$ & $\begin{array}{l}17 / 04 / 2017 \\
13: 35: 56\end{array}$ & & Aceito \\
\hline Folha de Rosto & folhaDeRostoAssinada.pdf & $\begin{array}{c}17 / 04 / 2017 \\
13: 34: 26 \\
\end{array}$ & $\begin{array}{l}\text { MÁRCIO PEREIRA } \\
\text { MORATO }\end{array}$ & Aceito \\
\hline $\begin{array}{l}\text { TCLE / Termos de } \\
\text { Assentimento / } \\
\text { Justificativa de } \\
\text { Ausência }\end{array}$ & DispensaTCLE.pdf & $\begin{array}{c}12 / 04 / 2017 \\
10: 38: 07\end{array}$ & $\begin{array}{l}\text { MÁRCIO PEREIRA } \\
\text { MORATO }\end{array}$ & Aceito \\
\hline $\begin{array}{l}\text { Projeto Detalhado / } \\
\text { Brochura } \\
\text { Investigador }\end{array}$ & ProjetoPesquisaGEPAJ.pdf & $\begin{array}{c}12 / 04 / 2017 \\
10: 37: 52\end{array}$ & $\begin{array}{l}\text { MARCIO PEREIRA } \\
\text { MORATO }\end{array}$ & Aceito \\
\hline
\end{tabular}

Situação do Parecer:

Aprovado

Necessita Apreciação da CONEP:

Não

Endereço: Avenida Bandeirantes, 3900

Bairro: VLA MONTE ALEGRE

UF: SP Municipio: RIBEIRAO PRETO

Telefone: (16)3315-0494

CEP: $14.040-907$

E-mail: $\propto$ epeogusp.br 


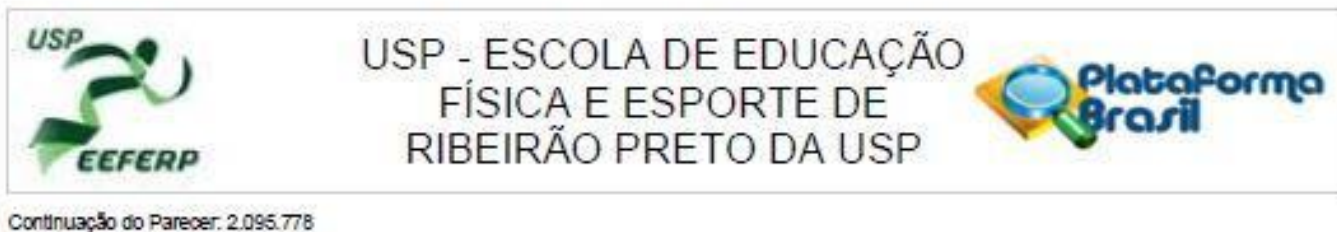

RIBEIRAO PRETO, 01 de Junho de 2017

Assinado por:

Carlos Roberto Bueno Júnior

(Coordenador)

Endereço: Avenida Bandeirantes, 3900

Bairro: VLA MONTE ALEGRE CEP: $14.040-907$

UF: SP Município: RIBEIRAO PRETO

Telefone: (16)3315-0494

E-mail: cepe0@usp.br

Pagins o4 de o4 